\title{
LUNG VOLUME UNDER SURGICAL ANAESTHESIA: THE EFFECT OF AVERTIN ON THE SUBTIDAL AIR ${ }^{1}$
}

\author{
By GUSTAF E. LINDSKOG AND A. D. SPICER \\ (From the Department of Surgery, Yale University School of Medicine, New Haven)
}

(Received for publication March 11, 1941)

Clinical and experimental evidence indicates that pulmonary hypoventilation and a decrease in pulmonary volume are fairly constant sequelae of operations performed in the abdominal cavity. Churchill and McNeill (1) observed a marked reduction in vital capacity following laparotomy. Beecher (2) and others have demonstrated that upper abdominal surgery causes a sharper reduction in vital capacity than lower abdominal types of operations, and that the reduction is greater for any given procedure in males than in females. Muller, Overholt and Pendergrass (3) found a significant rise in the level of the diaphragm following laparotomy and considered this a primary effect of the pneumoperitoneum, rather than a secondary effect of changes in the lung itself. Beecher (4) first studied the effect of laparotomy on the subtidal lung volume. ${ }^{2} \mathrm{He}$ demonstrated an average postoperative decrease of about 20 per cent, the drop becoming maximal on the fourth postoperative day, and returning toward the preoperative values during the second week. This significant study has suggested to us the necessity of noting the effect of surgical anaesthesia alone on the subtidal lung volume before factors incident to surgical manipulation enter the picture.

\section{MATERIALS AND METHODS}

The use of an inhalation anaesthetic precludes the employment of any alveolar gas dilution technic for determining lung volume, such as that of Christie (5) which is the best available. However, an anaesthetic agent such as avertin (tribromethanol) which is administered rectally and not excreted at all through the respiratory tract (6) lends itself admirably to this study.

A group of 17 preoperative surgical cases from the general surgical and gynecological services of the New Haven Hospital was selected. When the choice of anaesthesia was known to be basal avertin, the past respira-

1 This study was aided by a grant from the Fluid Research Fund of the Yale University School of Medicine.

2 The subtidal lung volume is here defined as the air content of the respiratory tract at the end of a normal tidal expiration. tory history of each case was carefully reviewed; any patient having recent or chronic symptoms was rejected, as was any subject with abnormal physical findings in the chest.

Preoperative control determinations of the subtidal volume were carried out according to the technic of Christie (5) sometimes in the post-absorption state on the day prior to operation, but more frequently on the morning of operation before any sedation had been given. Determinations of the subtidal volume were made in duplicate, at least, after a trial run to accustom the patient to breathing in a closed spirometer circuit. Particular care was taken to posture the patient in the supine horizontal position, with a single pillow under the head, and arms relaxed at the sides.

The patient was then returned to his room; a preliminary medication of morphine sulphate (grains $1 / 6$ or $1 / 4$ ) and atropine sulfate (grains $1 / 150$ or $1 / 100$ ) was given except in 2 cases (Cases 9 and 16) in which it was deliberately omitted for control purposes. Avertin in amylene hydrate was then administered rectally, the dosage and time being exactly noted. The usual dosage was equivalent to 70 to $90 \mathrm{mgm}$. per kilo of body weight. When the patient was asleep he was moved again to the laboratory and carefully adjusted to the above described position. A wire pharyngeal airway was inserted to support the tongue, and to avoid expiratory obstruction which may cause a considerable increase in subtidal volume (7). The jaws were supported by the anaesthetist, and the patient was connected with the spirometer, the pharyngeal airway being accommodated into the rubber mouthpiece and the lips carefully sealed with adhesive to prevent leakage. At least one, and if time and the surgeons' patience permitted, two determinations were made; the patient was then sent to the operating room, and the indicated procedure was carried out with supplementary local or inhalation anaesthesia. Before the patient was discharged from the hospital repeat determinations were made in 11 of the 17 cases.

\section{RESULTS}

The various data relevant to the 17 cases are best presented by the accompanying chart (Table I). It will be noted that the series included 7 males and 10 females with a wide selection of nonthoracic complaints.

Fourteen of the 17 cases showed a decrease in subtidal lung volume under the influence of avertin anaesthesia. The decrease in these 14 cases ranged 
GUSTAF E. LINDSKOG AND A. D. SPICER

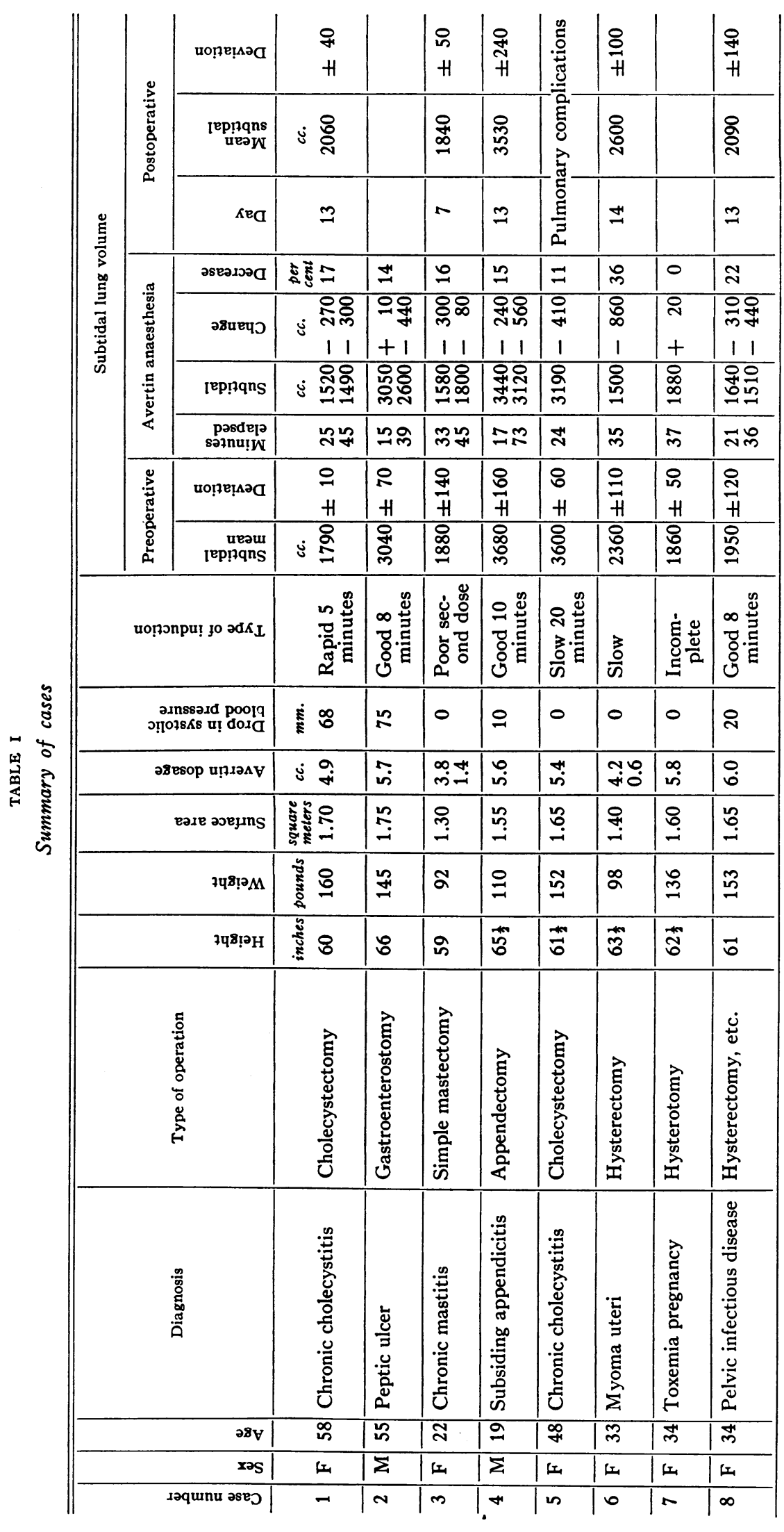




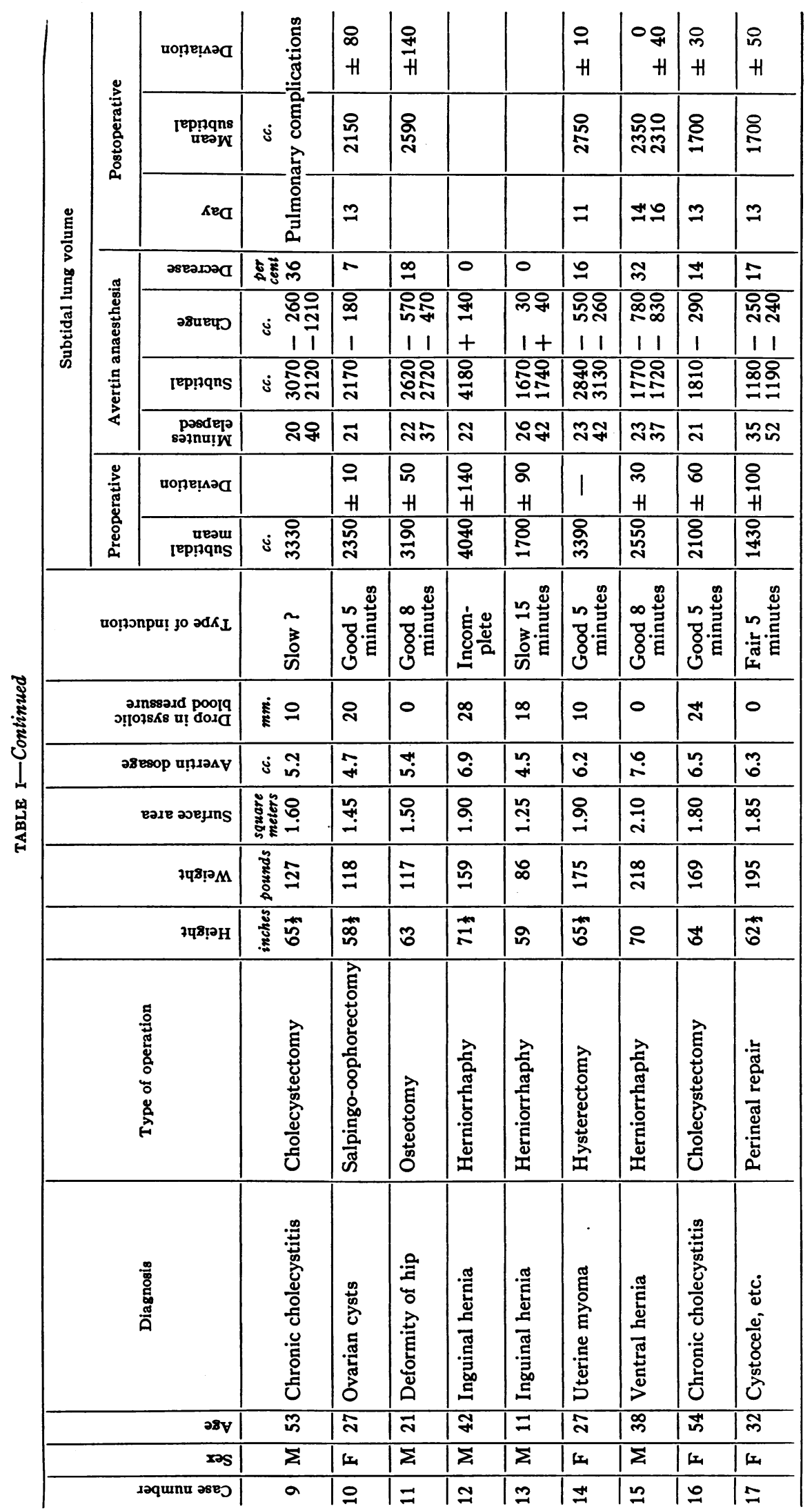




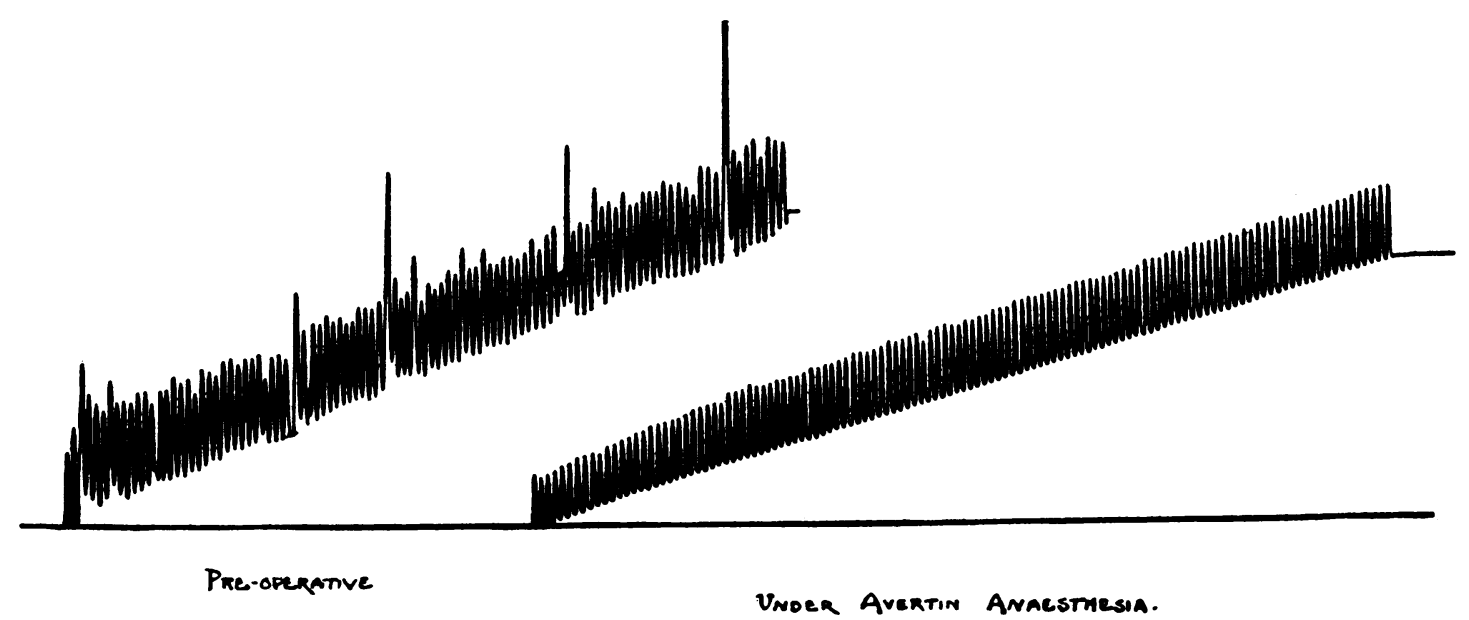

Fig. 1. Spirometer Tracings Before and During Avertin Anaesthesia. Case 1

from 180 to $1,210 \mathrm{cc}$. and averaged 510 cubic centimeters, or 19 per cent of the average subtidal volume. Of the 3 cases which failed to show any decrease, 2 (Cases 7 and 12) were never completely unconscious, reacting to sensory stimuli, moving and talking. The third case (Case 13) was very slow in induction; in $15 \mathrm{~min}$ utes he was sufficiently relaxed to permit introduction of a pharyngeal airway which was impossible in the other 2. No postoperative studies were made in these 3 , nor in 3 others because of death in 1 and postoperative pulmonary complications in 2 (Cases 2, 5, and 9). Of the remaining 11 in which postoperative determinations were made at least once before discharge, the subtidal lung volume had returned to the preoperative level or above in 5 , almost completely so in 3 , and not at all in 3 .

A marked regularity of respiration and smoothness in the spirometer tracings was noticed under a.vertin anaesthesia. There was a decrease in minute ventilation and oxygen consumption. These changes are well illustrated by Case 1 (Figure 1).

\begin{tabular}{|c|c|c|}
\hline \multicolumn{2}{|r|}{ Preoperative control } & Avertin \\
\hline $\begin{array}{l}\text { Duration of breathing period } \\
\text { Respiratory rate } \ldots \ldots \ldots \ldots \\
\text { Mean tidal } \ldots \ldots \ldots \ldots \ldots \\
\text { Minute volume } \ldots \ldots \ldots \ldots \ldots\end{array}$ & $\begin{array}{c}5 \frac{1}{2} \text { minutes } \\
18 \\
410 \mathrm{cc} . \\
7380 \mathrm{cc} \text {. per }\end{array}$ & $\begin{array}{c}7 \\
17 \\
340 \mathrm{cc} . \\
5780 \mathrm{cc} . \text { per }\end{array}$ \\
\hline Oxygen consumption. & $\begin{array}{r}\text { minute } \\
259 \mathrm{cc} \text {. per } \\
\text { minute }\end{array}$ & $\begin{array}{r}\text { minute } \\
183 \text { cc. per } \\
\text { minute }\end{array}$ \\
\hline $\begin{array}{l}\text { Ventilation equiv } \\
\text { Subtidal lung volur }\end{array}$ & 1790 cc. & $\begin{array}{l}3.1 \\
1500 \mathrm{cc} .\end{array}$ \\
\hline
\end{tabular}

* Number of liters of air respired for each $100 \mathrm{cc}$. oxygen consumed.

\section{DISCUSSION}

Expiration in the normal resting state is a passive phenomenon brought about by the elastic recoil of the lung and chest musculature, and aided by gravity and the weight of the abdominal viscera in some positions. The level at which expiration ceases is determined by a balance between the elasticity of the lung, and the resistance of the thoracic and abdominal wall. The prevailing muscle tone must therefore play a primary rôle in the establishment of the resting expiratory level, and likewise the subtidal lung volume. Anaesthesia of any type, if it reduces muscle tone, should reduce the air content of the lungs. Clinical observations now being completed in this laboratory (8) indicate that morphine sedation alone will reduce the subtidal volume in most subjects, but at a slower rate than avertin. One might predict that during natural sleep the same effect obtains and this has been observed. Spirometer tracings from one of our patients who unexpectedly but fortunately fell asleep during the course of a lung volume determination some months after pulmonary lobectomy (Figure 2) show a marked sagging of the expiratory level (to the extent of 500 cubic centimeters) with a rapid return to the original level when the patient was stimulated and awakened by a sudden noise.

Clinical experience with avertin indicates that the depth of anaesthesia and the degree of muscular relaxation are variable and unpredictable, depending on dosage, rate of absorption and excretion. There should therefore be a considerable variation 


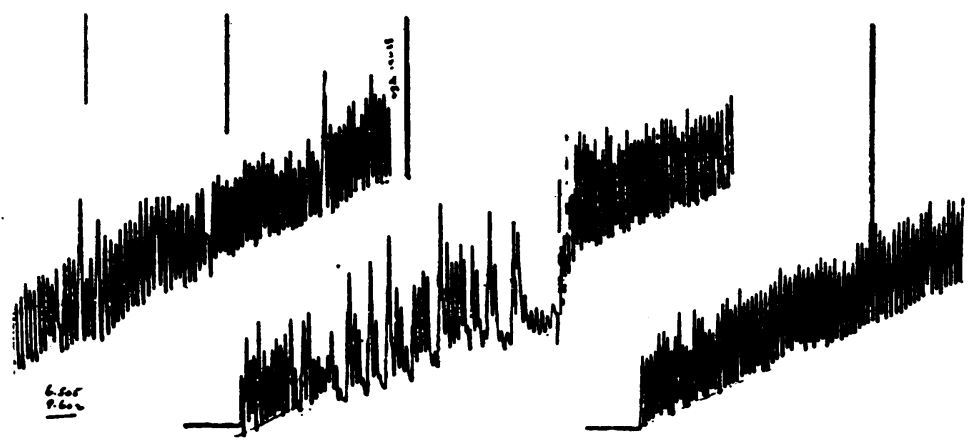

Fig. 2. Spirometer Tracings

Patient, undergoing routine post-lobectomy lung volume determinations, became drowsy and fell asleep during the course of the second (or middle) tracing. Note resumption of usual expiratory level when stimulated and fully awakened.

in the degree of lung volume decrease under the influence of this drug, and this seems to be the case. In 10 of the patients studied, it was possible to make two successive determinations under anaesthesia; it will be noted in Table I that, when the first determination was made less than 25 minutes after the rectal administration of the drug, the second determination was usually somewhat lower. This correlates with the fact that the maximal blood concentration ( 6 to $10 \mathrm{mgm}$. per cent) usually occurs about 30 minutes after administration, 85 per cent of the avertin having been absorbed at that time (6)

Of the 14 patients who demonstrated a decrease in subtidal lung volume under avertin, 5 were males, with an average decrease of $720 \mathrm{cc}$. and 9 females, with an average decrease of $390 \mathrm{cc}$. Whether this discrepancy has a bearing on the known preponderance of postoperative pulmonary complications in males cannot be definitely stated in view of the small number of cases involved.

Avertin exerts a strong depressant action on the medullary vasomotor centers. Five of the 17 cases showed an immediate drop of systolic blood pressure in excess of 20 millimeters. However, this group presented an average decrease of only $300 \mathrm{cc}$. in subtidal volume, as compared with 510 cc. for the whole group. It seems unlikely, therefore, that a primary vascular effect with redistribution of blood volume is responsible for the decrease in subtidal air.

\section{SUMMARY AND CONCLUSIONS}

1. A reduction in subtidal lung volume occurred in 14 of 17 subjects following the administration of avertin (tribromethanol) in basal anaesthetic doses. In the remaining 3 , anaesthesia was incomplete.

2. The maximum decrease was observed in the neighborhood of 30 minutes following administration of the drug when the circulating blood concentration of the drug is known to be highest.

3. The probable cause of this decrease is considered to be a diminution in muscle tone, with a consequent disturbance of the normal balance between the elastic lung and the supporting musculature of the thorax and abdomen.

4. Other evidences of respiratory depression are found and described.

\section{BIBLIOGRAPHY}

1. Churchill, E. D., and McNeill, D., Reduction in vital capacity following operation. Surg., Gynec. and Obst., 1927, 44, 483.

2. Beecher, H. K., The measured effect of laparotomy on the respiration. J. Clin. Invest., 1933, 12, 639.

3. Muller, G. P., Overholt, R. H., and Pendergrass, E. P., Postoperative pulmonary hypoventilation. Arch. Surg., 1929, 19, 1322.

4. Beecher, H. K., Effect of laparotomy on lung volume. Demonstration of a new type of pulmonary collapse. J. Clin. Invest., 1933, 12, 651.

5. Christie, R. V., The lung volume and its subdivisions. I. Methods of measurement. J. Clin. Invest., 1932, $11,1099$.

6. Sebening, W., Recent researches and clinical advances in avertin narcosis. Anaesth. Analg., 1932, 11, 145.

7. Lindskog, G. E., and Bradshaw, H. H., Unpublished data.

8. Post, F. A., Lindskog, G. E., and Bates, J. H., The effect of morphine sedation on the lung volume. (To be published.) 